\title{
Effects of black tea consumption and caffeine intake on depression risk in black tea consumers
}

\author{
Esma Asil, Mustafa Volkan Yilmaz, Hulya Yardimci
}

Ankara University, Nutrition and Dietetics.

\begin{abstract}
Background: The aim of this study was to compare black tea consumption and caffeine intake with depression status. Subjects and Methods: This study was conducted on 491 adults (M:169, F:322). The average daily caffeine intake of individuals was calculated using the amounts of caffeinated beverages they consumed daily and the caffeine contents of these beverages. The participants' depression status was determined using the Beck Depression Inventory (BDI). All of the research data were evaluated using STATA.

Results: According to BDI scores, $30.1 \%$ of participants had depression. Black tea was consumed by all of the participants and also had the highest consumption level of $620.1 \pm 90.4 \mathrm{~mL}$ and the mean caffeine intake of the participants was 629.5 $\pm 418.8 \mathrm{mg}$. Multivariate regression analyses showed that consuming more than 1 cup was protective against depression up to 4 cups. Moreover, a 450-600 mg caffeine intake also reduces the risk of depression than lower or higher intake levels. Conclusion: Our study suggests that black tea consumption up to 4 cups and caffeine intake between 450-600 mg can help protect against depression. Further studies are needed to better understand the protective effects of black tea and caffeine on depression.
\end{abstract}

Keywords: Caffeine, black tea, beck depression inventory, depression.

DOI: https://dx.doi.org/10.4314/ahs.v21i2.47

Cite as: Asil E, Yllmaz MV, Yardimci H. Effects of black tea consumption and caffeine intake on depression risk in black tea consumers. Afri Health Sci. 2021;21(2). 858-865. bttps:/ / dx.doi.org/10.4314/abs.v21i2.47

\section{Introduction}

Caffeine (1,3,7-trimethylxanthine) is a stimulator bioactive component of beverages such as coffee, tea, and energy drinks, as well as some foods like chocolate ${ }^{1}$. Caffeine is among the most widely ingested psychoactive substances ${ }^{2}$ and studies have found that it may contribute to psychiatric problems including depression ${ }^{3,4}$. Depression is a common mental disorder that, by definition, is symptomized by a deepening of one's mood, a loss of interest or enjoyment in life, a decrease of vigor, feelings of guilt or low self-esteem, a lack of appetite, an inability to achieve and maintain natural sleep, and a reduction in the ability to concentrate. Thus, depressive symptoms and disorders are prevalent in populations around the world. The World Health Organization (WHO) states that between 2005 and 2015 there was an increase of $15 \%$ in cases of depression and that more than 300 million people $(4.4 \%$ of the world's population) suffer from depression ${ }^{5}$. Consistent with global

\section{Corresponding author: \\ Mustafa Volkan Yilmaz, \\ Ankara University, Nutrition and Dietetics \\ Email: vyilmaz@ankara.edu.tr}

data, the WHO indicates that the prevalence of depressive disorder among the population of Turkey, unstandardized for age, is $4.4 \%{ }^{5}$. The prevalence of depression in adults were between $14.7 \%-25.8 \%$ in various studies conducted in Turkey ${ }^{6-8}$.

There are multiple studies evaluating the relationship between caffeine and depression in different populations ${ }^{4,9-12}$. Lucas, et $\mathrm{a}^{1.4}$ reported that depression risk decreased with the increase of caffeinated coffee consumption among women in the U.S. In a meta-analysis of studies about the relationship between coffee consumption and depression, consumption of up to 600 $\mathrm{mL}$ of coffee demonstrated an association with the reduced risk of depression ${ }^{14}$. Guo, et al..$^{15}$ found that individuals who consume four or more cups of coffee per day had a significantly lower risk of depression than those who consume one cup of coffee or less. Similarly, a study conducted in Finland with 2011 participants found that individuals who consumed tea on a daily basis showed fewer symptoms of depression ${ }^{13}$. It was determined that the high consumption of green tea within Japanese society was correlated with a low presence of depressive symptoms ${ }^{10}$. In a recent study, Yao, et 
al., ${ }^{16}$ using the data from Chinese Longitudinal Healthy Longevity Survey, found that a 1 cup or more level of tea consumption may protect against depression in the elderly.

Black tea consumption is prevalent in Turkey ${ }^{17,18}$. While in the early 2000 s Turkey ranked third $(2.3 \mathrm{~kg}$ per capita) after Northern Ireland and England in black tea consumption ${ }^{19}$ today, Turkey is leading the world with consumption of approximately $3.2 \mathrm{~kg}$ per capita ${ }^{20}$. Studies show black tea is the main source of caffeine consumption in Turkey ${ }^{17,18,21}$.

Understanding the impact of beverages that contain high levels of caffeine, which are widespread and consumed in relatively large amounts, on depression experienced by individuals is important for public health. However, research in Turkey on the relationship between depression and the consumption of caffeinated beverages to date is insufficient. The objective of this study is to expand this knowledge by comparing the consumption levels of black tea and the levels of caffeine intake with the depression status in adults.

\section{Method}

This study was conducted between December 2014 and February 2015 with the participation of 491 office workers (males: 169, females: 322; 33.5 \pm 10.9 years) living in Ankara. Black tea drinkers who consumed at least $100 \mathrm{~mL}$ of black tea per day were included in the study. Subjects who had a history of anxiety or depression and those who were using antidepressants were excluded from the study. The Beck Depression Inventory (BDI) was used to determine depression. Approval for the research was acquired from the Ethics Board of Ankara University (27/11/2014- 179/1345). Each participant in the research signed a consent form prior to his or her inclusion in the study.

Participants filled out a questionnaire that included socio-demographic (eg. education, income), anthropometric (eg. weight, height), and medical (eg. last measured systolic, diastolic blood pressure) information. The body weights and heights of the individuals who participated in the study were measured in accordance with the technique ${ }^{22}$. The body weights of the participants were measured with the Arzum AR580 device, while their heights were taken with a rigid measuring tape and the Body Mass Index (BMI) for each individual was calculated from the formula weight/height ${ }^{2}$ $\left(\mathrm{kg} / \mathrm{m}^{2}\right)$. The participants' BMIs were evaluated using the World Health Organization's classification system/ guidelines/protocol ${ }^{23}$.

\section{Beck Depression Inventory}

The depression status of the participants was determined using the Beck Depression Inevtory, developed by Beck, et al. in 1961. The scale measures the intensity of physical, emotional, cognitive, and motivational symptoms in depression, with the characteristics of self-assessment ${ }^{24}$. For instance, Turkish validity reliability was carried out by Teğin ${ }^{25}$ and Hisli ${ }^{26}$ in Turkey. Each item on the inventory is comprised of twenty-one categories and has 4 options. The scores obtained from the BDI vary between 0 and 63 . Scores between 0 and 9 are considered in the "normal range", while 10-16 are considered "light", 17 to 29 "moderate depression", and 30 to 63 points indicate "severe depression."

\section{Caffeinated Beverages Consumption}

In order to determine the amount in milliliters of caffeinated beverages consumed over the last 6 months by individuals, photos were shown from Photographed Food Catalogue - Measurements and Quantities ${ }^{27}$ and the quantities were estimated. The frequency of intake of these specified quantities was determined daily and multiplied by the consumption frequency coefficient (each day: 1.0; 5-6 times a week: 0.78; 3-4 times a week: 0.5 ; $1-2$ times a week: 0.21 ; once every 15 days: 0.06 ; once a month: 0.03 ; none: 0 ) in order to calculate the daily consumption amounts. One cup was measured as $200 \mathrm{~mL}$ for black tea and instant coffee, or as $55 \mathrm{~mL}$ for Turkish coffee (very strong black coffee served with the fine grounds in it).

The average caffeine intake of individuals was calculated using the caffeinated beverage amounts consumed daily and the caffeine contents of these beverages. Since traditional preparation of tea and Turkish coffee differs from preparation techniques used in other countries, the caffeine content of black tea and Turkish coffee was determined using the study of Hanci, et al. ${ }^{28}$ According to this study, the caffeine content of black tea and Turkish coffee was $80 \mathrm{mg} / 100 \mathrm{~mL}$ and $80 \mathrm{mg} / 55 \mathrm{~mL}$, respectively. The amount of caffeine in the remaining caffeine-containing beverages (cola, energy drinks, etc.) was determined using either the food label of each product or information from the USDA database $e^{28,29}$.

\section{Statistical Analysis}

In the analyses, BDI scores of $<10$ were classified as 
being within the normal range, while scores of $\geq 10$ were classified as depression. Tea consumption frequency was categorized as cups/day: $<1$ (reference), $1-2,2-3,3-4$ and $>4$, while caffeine intake was categorized as $\mathrm{mg} /$ day: 0-300 (reference), 300-450, 450-600, $600-750$ and $>750$. Variables that have been found in previous studies to potentially be associated with beverage consumption and depression were accounted for in the logistic regression models ${ }^{30-32}$. Multivariate odds ratios (OR) and confidence intervals (CI) were obtained, adjusting for sex, age (10-year groups), BMI ( $\mathrm{kg} / \mathrm{m} 2$ : $<18.5,18,5-25, \geq 25$ ), education level (Illiterate, elementary school, high school, and bachelor's degree), marital status (married and single), income level (low, middle, and high), smoking status (smoker or nonsmoker), alcohol consumption (yes or no), regular physical exercise (yes or no), diastolic and systolic blood pressures (normal, high-normal, and hypertension, according to the European Society of Cardiology's guidelines33). An alpha level of $<0.05$ was used as the threshold for statistical significance. All analyses were calculated electronically using STATA software.

\section{Results}

The general characteristics of the research participants, according to their BD scores, are presented in Table 1. The average caffeine intake of the participants was $629.5 \pm 418.8 \mathrm{mg}$. Average caffeine intake was higher in participants aged 30 to 39, elementary school graduates, married people, smokers, middle income earners, and those with higher diastolic blood pressure $(p<0.05)$. The prevalence of depression risk ( $\geq 10$ BD score) among these participants was $30.1 \%$. Higher depression risk is associated with age, BMI, marital status, income, smoking, alcohol consumption, regular physical activity, and systolic blood pressure $(\mathrm{p}<0.05)$.

The mean consumption of beverages and caffeine intake is shown in Table 2. As expected, black tea was consumed by all of the participants (n:491) and also had the highest consumption level $(620.1 \pm 90.4 \mathrm{~mL})$. Turkish coffee $(52.1 \%)$, instant coffee $(46.0 \%)$, and cola $(37.1 \%)$ were also regularly-consumed caffeinated beverages by the population studied. Black tea was the main source of caffeine $(576.4 \pm 407.4 \mathrm{mg})$.

Table 3 indicates that, in all models, black tea consumption levels higher than 1 cup and up to 4 cups, were protective against depression risk. Moreover, caffeine intake levels of 450-600 mg also reduce the risk of depression than lower or higher doses. 
Table 1: General characteristics of the participants according to their caffeine intake and BD scores

\begin{tabular}{|c|c|c|c|c|c|}
\hline Parameter & $\begin{array}{c}\text { Caffeine } \\
\text { intake (mg) }\end{array}$ & $\mathrm{p}$ value & $\begin{array}{c}\text { BD score } \\
<10 \\
(\mathrm{n}: 343) \\
\end{array}$ & $\begin{array}{c}\text { BD score } \\
\geq 10 \\
\text { (n: } 148) \\
\end{array}$ & $\begin{array}{c}\mathrm{p} \\
\text { value }\end{array}$ \\
\hline \multicolumn{6}{|l|}{ Sex } \\
\hline Male & $676.5 \pm 486.1$ & \multirow{2}{*}{$0.036^{\mathrm{a}}$} & 66.2 & 64.2 & \multirow{2}{*}{0,670} \\
\hline Female & $604.8 \pm 377.2$ & & 33.8 & 35.8 & \\
\hline \multicolumn{6}{|l|}{ Age } \\
\hline $20-29$ years & $581.0 \pm 427.0$ & \multirow[t]{4}{*}{$0.006^{\mathrm{a}}$} & 40.2 & 54.0 & \multirow{4}{*}{$0.035^{\mathrm{a}}$} \\
\hline $30-39$ years & $708.3 \pm 404.4$ & & 32.4 & 22.3 & \\
\hline $40-49$ years & $685.2 \pm 459.4$ & & 16.6 & 14.9 & \\
\hline $50+$ years & $526.0 \pm 297.8$ & & 10.8 & 8.8 & \\
\hline \multicolumn{6}{|l|}{ BMI } \\
\hline$<18.5$ & $596.2 \pm 335.9$ & \multirow{3}{*}{0.847} & 3.5 & 2.0 & \multirow{3}{*}{$0.007^{\mathrm{a}}$} \\
\hline $18.5-25$ & $639.2 \pm 439.7$ & & 47.5 & 62.8 & \\
\hline$\geq 25$ & $620.5 \pm 399.8$ & & 49.0 & 35.2 & \\
\hline \multicolumn{6}{|l|}{ Education Level (\%) } \\
\hline Illiterate & $515.6 \pm 242.3$ & \multirow{4}{*}{$0.016^{\mathrm{a}}$} & 6.2 & 2.0 & \multirow{4}{*}{0,069} \\
\hline Elementary school & $702.2 \pm 412.6$ & & 26.5 & 22.3 & \\
\hline High School & $670.6 \pm 470.2$ & & 26.5 & 24.3 & \\
\hline Bachelor's degree & $576.2 \pm 397.6$ & & 40.8 & 51.4 & \\
\hline \multicolumn{6}{|l|}{ Marital status (\%) } \\
\hline Married & $663.9 \pm 417.2$ & \multirow[t]{2}{*}{$0.019^{\mathrm{a}}$} & 60.9 & 46.6 & \multirow{2}{*}{$0,003^{a}$} \\
\hline Single & $584.5 \pm 417.5$ & & 39.1 & 53.4 & \\
\hline \multicolumn{6}{|l|}{ Income (\%) } \\
\hline Low & $583.1 \pm 385.8$ & \multirow{3}{*}{$0.006^{\mathrm{a}}$} & 37.0 & 56.1 & \multirow{3}{*}{$0,000^{\mathrm{a}}$} \\
\hline Middle & $701.3 \pm 462.9$ & & 46.4 & 29.7 & \\
\hline High & $567.3 \pm 355.8$ & & 16.6 & 14.2 & \\
\hline \multicolumn{6}{|l|}{ Smoking (\%) } \\
\hline Yes & $735.2 \pm 485.1$ & \multirow[t]{2}{*}{$0.000^{\mathrm{a}}$} & 24,5 & 34,5 & \multirow{2}{*}{$0,023^{\mathrm{a}}$} \\
\hline No & $590.5 \pm 384.3$ & & 75,5 & 65,5 & \\
\hline \multicolumn{6}{|l|}{ Alcohol consumption $(\%)$} \\
\hline Yes & $695.6 \pm 625.5$ & \multirow[t]{2}{*}{0.149} & 6.4 & 12.2 & \multirow{2}{*}{$0,030^{\mathrm{a}}$} \\
\hline No & $623.6 \pm 395.8$ & & 93,6 & 87,8 & \\
\hline \multicolumn{6}{|l|}{ Regular physical activity (\%) } \\
\hline Yes & $629.1 \pm 437.4$ & 0.495 & 26.0 & 18.9 & \\
\hline No & $429.6 \pm 413.4$ & & 74.0 & 81,1 & 0,093 \\
\hline Beck Depression Inventory Scores & & & $4.0 \pm 2.7$ & $18.5 \pm 8.0$ & $0,000^{\mathrm{a}}$ \\
\hline Systolic blood pressure & & & & & \\
\hline Normal (<129 mmHg) & $618.7 \pm 403.0$ & & 68.5 & 73.0 & \\
\hline High Normal (130-139 mmHg) & $608.1 \pm 422.4$ & 0.074 & 24.2 & 14.9 & $0.026^{\mathrm{a}}$ \\
\hline Hypertension $(\geq 140 \mathrm{mmHg})$ & $767.8 \pm 510.1$ & & 7.3 & 12.1 & \\
\hline Diastolic blood pressure & & & & & \\
\hline Normal (<85 mmHg) & $629.4 \pm 419.4$ & & 79.9 & 71.6 & \\
\hline High Normal (85-89 mmHg) & $547.8 \pm 386.2$ & $0.030^{\mathrm{a}}$ & 12.5 & 17.6 & 0.133 \\
\hline Hypertension ( $\geq 90 \mathrm{mmHg}$ ) & $763.0 \pm 439.7$ & & 7.6 & 10.8 & \\
\hline
\end{tabular}

Table 2: The mean consumption of beverages and caffeine intake

\begin{tabular}{lccc}
\hline & & Consumption Amount $(\mathrm{mL})$ & Caffeine Intake $(\mathrm{mg})$ \\
\hline Beverages & $\mathrm{n}(\%)$ & mean $\pm \mathrm{Sd}$ & mean $\pm \mathrm{Sd}$ \\
\hline Black Tea & $491(100.0)$ & $620.1 \pm 90.4$ & $576.4 \pm 407.4$ \\
Instant Coffee & $226(46.0)$ & $189.2 \pm 181.3$ & $61.1 \pm 65.0$ \\
Turkish Coffee & $256(52.1)$ & $37.0 \pm 30.5$ & $32.8 \pm 25.7$ \\
Green Tea & $33(6.7)$ & $159.2 \pm 124.5$ & $30.7 \pm 28.6$ \\
Cola & $182(37.1)$ & $118.5 \pm 159.0$ & $10.9 \pm 14.7$ \\
Energy Drinks & $7(1.4)$ & $143.4 \pm 185.8$ & $42.4 \pm 49.8$ \\
\hline
\end{tabular}


Table 3: Odds ratios and 95\% confidence intervals of $\mathrm{BD}$ scores according to different black tea consumption and caffeine intake levels

\begin{tabular}{|c|c|c|c|c|c|c|c|c|c|c|c|}
\hline \multirow[t]{2}{*}{$\begin{array}{l}\text { Black Tea } \\
\text { Consumption }\end{array}$} & \multicolumn{2}{|c|}{$\begin{array}{l}<1 \text { cup } \\
\text { n:23a/20 }\end{array}$} & \multicolumn{2}{|c|}{$\begin{array}{c}\text { 1-2 cup } \\
\text { n:73a/28b }\end{array}$} & \multicolumn{2}{|c|}{$\begin{array}{c}2-3 \text { cup } \\
n: 68^{a} / 25^{b}\end{array}$} & 3-4 cup & $\mathrm{n}: 78^{\mathrm{a}} / 26^{\mathrm{b}}$ & \multicolumn{2}{|c|}{$\begin{array}{l}>4 \text { cup } \\
\mathrm{n}: 101 / 49^{b}\end{array}$} & \multirow[b]{2}{*}{$\mathrm{p}$ value } \\
\hline & OR & $95 \% \mathrm{CI}$ & OR & $95 \% \mathrm{CI}$ & OR & $95 \% \mathrm{CI}$ & OR & $95 \% \mathrm{CI}$ & OR & $95 \% \mathrm{CI}$ & \\
\hline Model 1 & ref & ref & 0.44 & $0.21-0.93$ & 0.41 & $0.19-0.88$ & 0.39 & $0.18-0.82$ & 0.55 & $0.28-1.11$ & 0.041 \\
\hline Model 2 & ref & ref & 0.44 & $0.20-0.93$ & 0.40 & $0.18-0.86$ & 0.42 & $0.20-0.91$ & 0.59 & $0.29-1.20$ & 0.003 \\
\hline Model 3 & ref & ref & 0.44 & $0.20-0.95$ & 0.42 & $0.19-0.93$ & 0.45 & $0.21-0.98$ & 0.59 & $0.28-1.21$ & 0.000 \\
\hline \multirow{3}{*}{ Caffeine intake } & \multicolumn{2}{|c|}{$<300 \mathrm{mg}$} & \multicolumn{2}{|c|}{$300-450 \mathrm{mg}$} & \multicolumn{2}{|c|}{$450-600 \mathrm{mg}$} & \multicolumn{2}{|c|}{$600-750 \mathrm{mg}$} & \multicolumn{2}{|c|}{$>750 \mathrm{mg}$} & \\
\hline & \multicolumn{2}{|c|}{ n: $58^{a} / 38^{b}$} & \multicolumn{2}{|c|}{$n: 64^{a} / 26^{b}$} & \multicolumn{2}{|c|}{$\mathrm{n}: 77^{\mathrm{a}} / 20^{\mathrm{b}}$} & \multicolumn{2}{|c|}{$\mathrm{n}: 48^{\mathrm{a}} / 18^{\mathrm{b}}$} & \multicolumn{2}{|c|}{$n: 96^{a} / 46^{b}$} & \\
\hline & OR & $95 \% \mathrm{Cl}$ & OR & $95 \% \mathrm{Cl}$ & OR & $95 \% \mathrm{CI}$ & OR & $95 \% \mathrm{Cl}$ & OR & $95 \% \mathrm{CI}$ & $p$ value \\
\hline Model 1 & ref & ref & 0.68 & $0.36-1.26$ & 0.40 & $0.21-0.77$ & 0.61 & $0.31-1.21$ & 0.74 & $0.43-1.28$ & 0.003 \\
\hline Model 2 & ref & ref & 0.64 & $0.34-1.20$ & 0.42 & $0.22-0.82$ & 0.70 & $0.35-1.40$ & 0.80 & $0.46-1.40$ & 0.003 \\
\hline Model 3 & ref & ref & 0.57 & $0.30-1.09$ & 0.39 & $0.20-0.77$ & 0.64 & $0.31-1.31$ & 0.71 & $0.40-1.27$ & 0.000 \\
\hline Model 4 & ref & ref & 0.56 & $0.29-1.07$ & 0.40 & $0.20-0.78$ & 0.66 & $0.32-1.38$ & 0.81 & $0.44-1.49$ & 0.000 \\
\hline
\end{tabular}

Model 1: Sex, age, BMI; Model 2: Model $1+$ education level, marital status, income; Model 3: Model 2 + smoking status, alcohol consumption, regular physical activity, diastolic and systolic blood pressure; Model 4: Model $3+$ Caffeine intake other than black tea

a: BDI score $<10 \quad$ b: BDI score $\geq 10 \quad 1$ cup: $200 \mathrm{~mL}$

\section{Discussion}

This study aimed to investigate the relationship of caffeine intake and black tea consumption, which is the main source of caffeine among the population of Turkey, with depression. Multiple studies have reported on the relationship between caffeine and depression ${ }^{34-37}$. Our study strongly suggests that the participants' daily caffeine intake through beverages was $629.5 \pm 418.8 \mathrm{mg}$ (and $450-600 \mathrm{mg} / \mathrm{d}$ caffeine level) has a protective effect against depression, according to BD scores. In addition, the prevalence of depression was lower in participants who consumed between 1 to 4 cups of black tea per day, after adjustment for potential confounders. Similar to these findings, previous studies have supported inverse relationships between caffeine and depression. Smith, et al. determined that the prevalence of clinical depression was $4.1 \%$ in individuals who consumed more than $260 \mathrm{mg}$ of caffeine daily, whereas it was $33.7 \%$ among those who did not consume caffeine $(\mathrm{p}<0.05)^{34}$. In another study, a J-shaped relationship was found between caffeine intake and post-partum depres$\operatorname{sion}^{38}$. In other recent meta-analysis, it was shown that 68 to $509 \mathrm{mg}$ of caffeine intake significantly decreased the risk of depression ${ }^{39}$. The relationship between caffeine and depression varies with the amount of daily caffeine intake ${ }^{4,13,38,39}$. Consistent with these findings, the present study found that $450-600 \mathrm{mg}$ of caffeine intake caused a $61 \%$ reduction in the risk of depression compared to a 0-300 mg caffeine intake. (Table 3).

The high levels of tea consumed could have developed in the consumer a tolerance for caffeine 40 . In that case, consumption above a certain amount, when continuous, could decrease the positive effects of caffeine. Since the effect of caffeine on depression varies according to the amount of caffeine intake, accounting for the habitual consumption of caffeine-containing drinks is also important.

In this study, the caffeine intake of participants was higher than it was in much of the existing literature 4,9,10,34,41 and black tea was the major source of caffeine. Next to water, black tea is the most widely consumed traditional beverage in Turkey ${ }^{17}$. Euromonitor International reported that black tea consumption in Turkey was the highest per person in the world ${ }^{42}$. In several studies conducted in Turkey, black tea was found to be the most preferred beverage for breakfast and with snacks 18 as well as the most consumed beverage overall ${ }^{17}$. The findings that supports this information were also revealed in this study. Consumption of black tea was $620.1 \pm 90.4 \mathrm{~mL}$, which exceeds that of any other beverage (Table 2 ).

The protective effect of tea against depression has been demonstrated repeatedly ${ }^{13,16,43,44}$. Hintikka, et al. found an inverse correlation between tea consumption in adults and their scores on the BDI ${ }^{13}$. Moreover, it was stated that the individuals who consume tea were less depressed than those who do not $(p<0.05)$. The same study did not find features of depression in individuals who drank more than five cups of tea daily ${ }^{13}$. A similar study determined that those with high tea consumption levels had lower levels of symptoms of depression ${ }^{43}$. Moreover, in a meta-analysis evaluating this subject, an inverse relationship was found between tea consumption and depression, and also that those who consumed 
more than three cups of tea daily had reduced risk of depression by $37.0 \%{ }^{44}$. Consistent with existing literature, in this study, it was found that consumption of 1 to 4 cups of black tea decreased the risk of depression by approximately $55.0 \%$ (Table 3 ).

The mechanism underlying the relationship between tea consumption and a risk of depression is still under investigation. Some studies have illustrated that the relationship between caffeine and depression results from caffeine's impact on the nervous system ${ }^{44,45}$. Caffeine and caffeine's largest metabolite adenosine receptors increase the flexibility of hippocampal CA2 neurons in the brain, reducing the risk of depression in individuals who consume coffee ${ }^{46,47}$. It is generally considered that the safe daily dosage of caffeine intake is less than $500 \mathrm{mg}{ }^{48}$ however according to the Dietary Guidelines for Americans 2015-2020, caffeine intake up to $400 \mathrm{mg}$ per day can be acceptable ${ }^{41}$. In addition to caffeine, beverages such as coffee and tea contain antioxidants and phytochemicals, which might be factors in low levels of depression ${ }^{15}$. A recent mechanism study showed that black tea L-theanine, epigallocatechin gallate, and theaflavins associated with anti-depressive effects through multiple pathways. These pathways include up-regulation of ERK/CREB/BDNF signaling, down-regulation of NF-kB signaling, and modulating dopaminergic activity and the gut-brain axis ${ }^{49}$.

The current literature examining associations between caffeine intake and depression has been mainly carried out in Western countries with high levels of coffee consumption or in Eastern countries with levels of high green tea consumption. Uniquely, Turkey has the highest per capita consumption level of black tea. Furthermore, the country's traditional brewing style (15-30 min. brewing) increases the caffeine and polyphenol content of black tea, which results in higher intakes of caffeine and polyphenols ${ }^{50}$. As expected, the results of this study indicated that black tea had the highest consumption level among all caffeine-containing beverages. The consumption of 1 to 4 cups of black tea (and 450-600 $\mathrm{mg}$ caffeine intake) was protective against depression. This protective effect may be the result of bioactive components as well as of caffeine itself. To better understand this protective effect, more studies of people who consume high amounts of black tea are needed.

\section{Limitations of Study}

The sample of this research may be expanded to pro- duce better results that more fully describe the population. In our study, all of the participants were habitual black tea consumers which caused us to select our reference group from the lowest level tea consumers. Adding a "non-consumer" group may improve the results of further studies. Together with the food consumption frequency of the participants, the evaluation of their food consumption records will also more accurately determine their daily caffeine intake. Throughout the research process, the participants were not examined, nor were sub-clinical depression diagnoses recorded by a physician. Personal statements regarding the symptoms of depression were taken as the basis. A more robust diagnostic method should be used in further studies.

\section{Conflict of Interest}

The authors declare no potential conflicts of interests with respect to the authorship and/or publication of this article.

\section{Acknowledgments}

The authors thank Ms. Ş. Bölükbaş, Ms. G. Şimşek, and Ms. R. Erdogan for their assistance with the study. Thank you, also, to S. Barlas and J. Kuras for their careful reading and language editing of this document.

\section{References}

1. Dawkins L, Shahzad F-Z, Ahmed SS, Edmonds CJ. Expectation of having consumed caffeine can improve performance and mood. Appetite. 2011;57(3):597-600.

2. Greden J, Pomerleau O. Caffeine-related disorders and nicotine-related disorders. Kaplan HI, Sadock BJ, Cancro R, (Eds). Comprehensive Textbook of Psychiatry $6^{\text {th }}$ ed Baltimore: Williams \& Wilkins. 1995:806-811. 3. Broderick P, Benjamin A, Dennis L. Caffeine and psychiatric medication interactions: a review. The $J$. Okla. State. Med. Assoc. 2005;98(8):380-384.

4. Lucas M, Mirzaei F, Pan A, et al. Coffee, caffeine, and risk of depression among women. Arch. Intern. Med. 2011;171(17):1571-1578.

5. Depression and Other Common Mental Disorders: Global Health Estimates. Geneva: World Health Organisation 2017.

6. Özyurt BC, Deveci A. The Relationship between Domestic Violence and the Prevalence of Depressive Symptoms in Married Women between 15 and 49 Years of Age in a Rural Area of Manisa, Turkey. Türk Psikiyatr. De. 2010;21(1):1-7.

7. Kayahan B, Altıntoprak E, Karabilgin S, Öztürk Ö. The relationship between risk factors and depression scores, and depression prevalence among wom- 
en between 15-49 [year]s age. Anadolu Psikiyatri Derg. 2003;4(4):208-219.

8. Ünsal A, Ayranci Ü, Tozun M. Prevalence of depression and its relationship with sociodemographic characteristics among women in a rural town of western Turkey. Anadolu Psikiyatri Derg. 2008;9(3):148.

9. Ruusunen A, Lehto SM, Tolmunen T, Mursu J, Kaplan GA, Voutilainen S. Coffee, tea and caffeine intake and the risk of severe depression in middle-aged Finnish men: the Kuopio Ischaemic Heart Disease Risk Factor Study. Public Health Nutr. 2010;13(8):1215-1220. 10. Pham NM, Nanri A, Kurotani K, et al. Green tea and coffee consumption is inversely associated with depressive symptoms in a Japanese working population. Public Health Nutr. 2014;17(3):625-633.

11. Park R, Moon J. Coffee and depression in Korea: the fifth Korean National Health and Nutrition Examination Survey. Eur. J. Clin. Nutr. 2015;69(4):501.

12. Iranpour S, Sabour S. Inverse association between caffeine intake and depressive symptoms in US adults: data from National Health and Nutrition Examination Survey (NHANES) 2005-2006. Psychiatry. Res. 2019;271:732-739.

13. Hintikka J, Tolmunen T, Honkalampi K, et al. Daily tea drinking is associated with a low level of depressive symptoms in the Finnish general population. Eur. J. Epidemiol. 2005;20(4):359-363.

14. Grosso G, Micek A, Castellano S, Pajak A, Galvano F. Coffee, tea, caffeine and risk of depression: A systematic review and dose-response meta-analysis of observational studies. Mol. Nutr. Food. Res. 2016;60(1):223234.

15. Guo X, Park Y, Freedman ND, et al. Sweetened beverages, coffee, and tea and depression risk among older US adults. PloS One. 2014;9(4):e94715.

16. Yao Y, Chen H, Chen L et al. Type of Tea Consumption and Depressive Symptoms in Older Adults. BMC Geriatrics. 2020 (Ahead of publication 10.21203/ rs.3.rs-104524/v1)

17. Yardimci H, Özdoğan Y, Asil E, Hovland E, Özçelik A. An Evaluation of Adults' Water and Fluid Consumption. Online J Health Allied Scs. 2016;15(3):8.

18. Nergiz-Unal R, Akal Yildiz E, Samur G, Besler HT, Rakicioğlu N. Trends in fluid consumption and beverage choices among adults reveal preferences for ayran and black tea in central Turkey. Nutr. Diet. 2017;74(1):74-81. 19. Güneş S. Türk Çay Kültürü Ve Ürünleri. Milli Folklor. 2012;24(94).

20. Quartz. Annual per capita tea consumption worldwide as of 2016, by leading countries (in pounds). https://www.statista.com/statistics/507950/glob- al-per-capita-tea-consumption-by-country/. Published 2016. Accessed 1/18, 2019.

21. Köksal E, Yardımcı H, Kocaadam B, Deniz Güneş B, Yılmaz B, Karabudak E. Relationship between dietary caffeine intake and blood pressure in adults. Int. J. Food Sci. Nutr. 2017;68(2):227-233.

22. Gibson RS. Principles of Nutritional Assessment. Oxford University Press, New York, USA. 2005.

23. World Health Organisation. Body Mass Index (on-line). Available at: "http://www.euro.who. int/en/health-topics/disease-prevention/nutrition/a-healthy-lifestyle/body-mass-index-bmi."Accessed July 28, 2019.

24. Beck AT, Ward CH, Mendelson M, Mock J, Erbaugh J. An inventory for measuring depression. Arch. Gen. Psychiatry. 1961;4(6):561-571.

25. Tegin B. Depresyonda Bilişsel Süreçler: Beck Modeline Göre Bir İnceleme (Cognitive Processes in Depression: A study according to Beck's Model) Turk J Psychol. 1987;6(21):116-121.

26. Hisli N. Beck Depresyon Envanterinin Geçerligi Uzerine Bir Calısma (A study on the validity of BDI). Turk J Psychol. 1989;22:118-126.

27. Rakicioglu N, Tek N, Ayaz A. Food and food photo catalog: dimensions and volumes. Ata Ofset Matbaacilik, Ankara, Turkey. 2012.

28. Hanci M, Bakirci S, Bayram S, et al. Caffeine levels in Turkish coffee and some beverages sold in Turkey. Duqce Med J. 2013;15(3):34-38.

29. United States Department of Agriculture. USDA Food Composition Databases (on-line). Available at "https://ndb.nal.usda.gov" Accessed January 24, 2019. 30. Klesges RC, Ray JW, Klesges LM. Caffeinated coffee and tea intake and its relationship to cigarette smoking: An analysis of the Second National Health and Nutrition Examination Survey (NHANES II). J Subst Abuse. 1994;6(4):407-418.

31. Andrew V. Kuczmarski, Nancy Cotugna, Marc A. Mason, Michele K. Evans, Zonderman AB. Depression and Cognitive Impairment Are Associated with Low Education and Literacy Status and Smoking but Not Caffeine Consumption in Urban African Americans and White Adults. Journal of Caffeine Research. 2015;5(1):31-41.

32. Meng L, Chen D, Yang Y, Zheng Y, Hui R. Depression increases the risk of hypertension incidence: a meta-analysis of prospective cohort studies. J Hypertens. 2012;30(5):842-851.

33. Zanchetti A, Dominiczak A, Coca A, et al. 2018 ESC/ESH Guidelines for the management of arterial hypertension. Eur. Heart. J. 2018;39(33):3021-3104. 
34. Smith AP. Caffeine, cognitive failures and health in a non-working community sample. Hum. Psychopharmacol. Clin. 2009;24(1):29-34.

35. Tanskanen A, Tuomilehto J, Viinamäki $\mathrm{H}$, et al. Heavy coffee drinking and the risk of suicide. Eur. J. Epidemiol. 2000;16(9):789-791.

36. Benko CR, Farias AC, Farias LG, et al. Potential link between caffeine consumption and pediatric depression: a case-control study. BMC Pediatrics. 2011;11:73. 37. Silverman K, Evans SM, Strain EC, Griffiths RR. Withdrawal syndrome after the double-blind cessation of caffeine consumption. N. Engl. J. Med. 1992;327(16):1109-1114.

38. Iranpour S, Kheirabadi GR, Heidari-Beni M, Maracy MR. Association between caffeine consumption during pregnancy and postpartum depression: A population-based study. J. Caffeine Res. 2017;7(1):1-6.

39. Wang L, Shen X, Wu Y, Zhang D. Coffee and caffeine consumption and depression: A meta-analysis of observational studies. Aust. N. Z. J. Psychiatry. 2016;50(3):228-242.

40. Evans SM, Griffiths RR. Caffeine tolerance and choice in humans. Psychopharmacology. 1992;108(1-2):5159.

41. Lieberman HR, Agarwal S, Fulgoni III VL. Daily Patterns of Caffeine Intake and the Association of Intake with Multiple Sociodemographic and Lifestyle Factors in US Adults Based on the NHANES 2007-2012 Surveys. J. Acad. Nutr. Diet. 2019;119(1):106-114.
42. Statista. Annual per capita tea consumption worldwide as of 2016,by leading countries (on-line). Available at "https://www.statista.com/statistics/507950/global-per-capita-tea-consumption-by-country/" Accessed January 12, 2019.

43. Feng L, Li J, Kua EH, et al. Association between tea consumption and depressive symptoms in older Chinese adults. J. Am. Geriatr. 2012;60(12):2358-2360.

44. Dong X, Yang C, Cao S, et al. Tea consumption and the risk of depression: A meta-analysis of observational studies. Aust. N. Z. J. Psychiatry. 2015;49(4):334-345.

45. Omagari K, Sakaki M, Tsujimoto Y, et al. Coffee consumption is inversely associated with depressive status in Japanese patients with type 2 diabetes. J Clin. Biochem. Nutr. 2014;55(2):135-142.

46. Morelli M, Carta AR, Kachroo A, Schwarzschild MA. Pathophysiological roles for purines: adenosine, caffeine and urate. Prog Brain Res. 2010;183:183-208.

47. Simons SB, Caruana DA, Zhao M, Dudek SM. Caffeine-induced synaptic potentiation in hippocampal CA2 neurons. Nat Neurosci. 2012;15:23-25.

48. Sepkowitz KA. Energy drinks and caffeine-related adverse effects. JAMA. 2013;309(3):243-244.

49. Rothenberg DO, Zhang L. Mechanisms underlying the anti-depressive effects of regular tea consumption. Nutrients. 2019;11(6):1361.

50. Fernando CD, Soysa P. Extraction kinetics of phytochemicals and antioxidant activity during black tea (Camellia sinensis L.) brewing. Nutr J. 2015;14:74. 